\title{
Marked progress in AL amyloidosis survival: a 40-year longitudinal natural history study
}

\author{
Andrew Staron (iD ${ }^{1,2}$, Luke Zheng (iD ${ }^{3}$, Gheorghe Doros (D) $^{1,3}$, Lawreen H. Connors $\mathbb{D}^{1,4}$, Lisa M. Mendelson (iD) ${ }^{1}$, Tracy Joshi ${ }^{1}$ and \\ Vaishali Sanchorawala (iD ${ }^{1,2}$ 凶
}

(c) The Author(s) 2021

The recent decades have ushered in considerable advancements in the diagnosis and treatment of systemic light chain (AL) amyloidosis. As disease outcomes improve, AL amyloidosis-unrelated factors may impact mortality. In this study, we evaluated survival trends and primary causes of death among 2337 individuals with AL amyloidosis referred to the Boston University Amyloidosis Center. Outcomes were analyzed according to date of diagnosis: 1980-1989 (era 1), 1990-1999 (era 2), $2000-2009$ (era 3), and 2010-2019 (era 4). Overall survival increased steadily with median values of 1.4, 2.6, 3.3, and 4.6 years for eras 1-4, respectively $(P<0.001)$. Six-month mortality decreased over time from $23 \%$ to $13 \%$. Wide gaps in survival persisted amid patient subgroups; those with age at diagnosis $\geq 70$ years had marginal improvements over time. Most deaths were attributable to diseaserelated factors, with cardiac failure (32\%) and sudden unexpected death (23\%) being the leading causes. AL amyloidosis-unrelated mortality increased across eras (from $3 \%$ to $16 \%$ of deaths) and with longer-term survival ( $29 \%$ of deaths occurring $>10$ years after diagnosis). Under changing standards of care, survival improved and early mortality declined over the last 40 years. These findings support a more optimistic outlook for patients with $\mathrm{AL}$ amyloidosis.

Blood Cancer Journal (2021)11:139; https://doi.org/10.1038/s41408-021-00529-w

\section{INTRODUCTION}

Systemic light chain (AL) amyloidosis was historically regarded as an inevitably fatal disease. Prior to effective treatments against the underlying plasma cell dyscrasia, prognosis was dismal with an expected survival of 13 months and, among those with symptomatic heart involvement, only 6 months [1-3]. A turning point came in the 1990s with the introduction of high-dose melphalan and autologous stem cell transplantation (HDM/SCT) for $\mathrm{AL}$ amyloidosis $[4,5]$. This treatment modality offered a more favorable prognosis for carefully selected patients [6]. However, options remained limited for $65-75 \%$ of newly diagnosed patients who were ineligible for HDM/SCT. A wave of new therapeutics for AL amyloidosis arrived after 2010, including bortezomib-based regimens, novel proteasome inhibitors (PI), next-generation immunomodulatory drugs (IMiD), and anti-CD38 monoclonal antibodies [7-13]. Beyond treatments, standardized riskstratification and treatment response assessment, owing to the advent of the serum-free light-chain assay and organ dysfunction biomarkers in the 2000s, contributed to a much-improved outlook for this rare disease [14-19].

The magnitude of impact on survival from these advancements is partially defined by the observed increase in disease prevalence of $12 \%$ per year, despite an unchanging incidence rate $[20,21]$. At major referral centers for AL amyloidosis, survival rates have improved over the years [22-24]. Long-term survival is becoming more common with upwards of 1 in 5 patients now attaining longevity of 10 years after diagnosis [25]. Even longer-term survival of $15-20$ years is seen in $\sim 30 \%$ of patients treated with $\mathrm{HDM} / \mathrm{SCT}[6,26,27]$. As survival improves, there may be a shift in primary causes of death among patients with $\mathrm{AL}$ amyloidosis. Leading causes during early course of disease include progressive heart failure, arrhythmias, and sudden unexpected death $[1,28,29]$. Causes of death later in the course of disease are less clear. The long-term effects on mortality of $A L$ amyloidosis and its treatments, along with co-morbid conditions, have yet to be clarified in a broad patient population.

Here, we illustrate the progress made in the survival of patients with AL amyloidosis. Unlike prior reports, we focus on the distribution of survival improvements across various patient subgroups, in order to identify those with the highest unmet needs. We also examine primary causes of death and their relation to $\mathrm{AL}$ amyloidosis to better inform disease biology and natural history over time.

\section{METHODS \\ Data source and study population}

Patients with AL amyloidosis diagnosed between January 1980 and December 2019 were identified from the prospectively maintained database at the Amyloidosis Center at Boston University School of Medicine and Boston Medical Center. Those with localized AL amyloidosis, myeloma-associated AL amyloidosis, and B cell lymphoproliferative disorder-associated AL amyloidosis were excluded from analysis due to

\footnotetext{
${ }^{1}$ Amyloidosis Center, Boston University School of Medicine and Boston Medical Center, Boston, MA, USA. ${ }^{2}$ Section of Hematology and Oncology, Boston University School of Medicine and Boston Medical Center, Boston, MA, USA. ${ }^{3}$ Department of Biostatistics, Boston University School of Public Health, Boston, MA, USA. ${ }^{4}$ Department of Pathology and Laboratory Medicine, Boston University School of Medicine and Boston Medical Center, Boston, MA, USA. ${ }^{\circledR}$ email: Vaishali.Sanchorawala@bmc.org
} 
differing risks and treatment approaches [30-35]. When necessary, typing of amyloidogenic protein was performed by immunohistochemistry, immunogold electron microscopy (IG-EM) or liquid chromatography and tandem mass spectrometry $\left(\mathrm{LCMS}^{2}\right)$. Patients with indeterminate amyloid type were excluded. A total of 2337 patients met criteria for the diagnosis of systemic AL amyloidosis alone, with positive Congo red staining of biopsy specimen and plasma cell clonality in the context of appropriate clinical syndrome. All patients provided written consent for research under the approval of the Institutional Review Board and in accordance with the Declaration of Helsinki (ClinicalTrials.gov Identifier: NCT00898235).

Individuals were categorized into 4 strata according to the date of tissue diagnosis, each at 10-year intervals: 1980-1989 (era 1), 1990-1999 (era 2), 2000-2009 (era 3), and 2010-2019 (era 4). Descriptive data included demographics, hematologic parameters, organ system involvement and treatments. After 2005, organ involvement was defined according to the consensus criteria of the International Society of Amyloidosis (ISA) [36]. Prior to this, it was determined by experts at the institution using available clinical information. When assessing organ involvement, only the heart, kidney, liver, and nervous system were included. Cardiac biomarker stage was assigned based on predefined criteria [16] for individuals diagnosed after 2007, when B-type natriuretic peptide (BNP, normal $<53.2 \mathrm{pg} / \mathrm{mL}$ ) and troponin-I (normal $<0.013 \mathrm{ng} / \mathrm{mL}$ ) were both available.

For treatment analysis, all plasma cell-directed therapies received throughout the course of disease were counted. Non-plasma cell-directed therapies were excluded (e.g., doxycycline, $n=14$; NEOD001, $n=10$ ). Treatment data were confirmed for 1581 patients. The remaining patients did not receive therapy due to early death $(n=253)$ and other reasons (e.g., absence of vital organ involvement, poor performance status or patient choice, $n=82$ ), or treatment could not be confirmed due to lack of follow-up $(n=421)$. Therapies were classified as: HDM/SCT; oral melphalan-based regimen; PI-based regimen; IMiD-based regimen; antiCD38 monoclonal antibody; or other treatment (e.g., anthracycline with dexamethasone, dexamethasone monotherapy).

\section{Survival and cause of death ascertainment}

Vital status was verified by yearly clinical evaluations. Contact by letter and/or phone was established with patients who did not return for follow-up. If contact could not be established, survival information was ascertained from the U.S. Social Security Death Index. Data cutoff was October 2020. For deceased patients, the cause of death and its relation to $\mathrm{AL}$ amyloidosis was determined by treating physicians using information from medical documentation, referring physicians, family members and/or official documents of death. Sufficient data were accessible on $1243(75 \%)$ of 1660 deaths to confidently assign as related or unrelated to AL amyloidosis. Deaths were defined as AL amyloidosisrelated when clinical information indicated progression of amyloid organ disease or complications from plasma cell-directed therapy. Deaths occurring while in remission, off treatment and without evidence of amyloid organ disease progression, or with clear relation to a co-morbid condition were considered AL amyloidosis-unrelated. The primary cause of death was available for 1160 (70\%) cases and categorized as: organ failure; sudden unexpected death (e.g., occurring during sleep, or shortly after symptom onset in patients whose disease was not severe enough to explain rapid clinical deterioration); infection and/or sepsis; treatment-related complication; major vascular event (e.g., stroke, myocardial infarction, pulmonary embolism or other thromboembolic event); hemorrhage; malignancy; or other cause (e.g., trauma/suicide, cachexia, bowel obstruction, dementia).

\footnotetext{
Statistical analysis

Data were presented in chronological order, unless stated otherwise. For descriptive analyses, chi-square and one-way ANOVA tests were used to make comparisons between eras. If data were missing, the number of complete cases $(N)$ were specified. There were more incomplete data during the earlier eras, largely due to variables not yet being included in the database or the unavailability of biomarker tests. Overall survival (OS) was measured from date of diagnosis to death (any cause) or last follow-up (censored), and illustrated using Kaplan-Meier method with differences between eras compared using the log-rank test. Survival probabilities and $95 \%$ confidence intervals (Cl) were calculated. Early mortality was defined as deaths occurring within 6 months of diagnosis. Statistical computations were performed by SAS version 9.4 and $\mathrm{R} 4.0 .2$ software with $P<0.05$ set as statistically significant.
}

\section{RESULTS}

The number of individuals in each stratum was: era 1, $n=185(8 \%$ of all patients); era 2, $n=575$ (25\%); era 3, $n=865$ (37\%); and era $4, n=712$ (30\%). Median time to evaluation at the Amyloidosis Center from diagnosis was 2 months (interquartile range, 1-5 months). Patient and disease characteristics at initial presentation to the referral center are shown in Table 1. Over the 40 -year period, median age at diagnosis increased by 4 years. The proportion of patients with age $\geq 75$ years increased threefold. There was a downward trend in the difference between involved and uninvolved free light chains (dFLC). This was paralleled by a shortening time interval to diagnosis from patient-reported symptom onset, from 10 months in era 1 to 6 months in era 4 $(P=0.065)$. Differences in organ system involvement and biomarkers had no apparent pattern by chronological era.

The assortment of plasma cell-directed treatments (including first and subsequent lines) received by individuals from each stratum are presented in Table 1. Oral melphalan-based regimens were the sole option during era 1. Some individuals from eras 2 and 3 survived long enough to receive the novel agents introduced after 2010. HDM/SCT was the most common treatment, used for $31 \%(n=723)$ of patients. Use of HDM/SCT declined from eras 2 to 4 . Meanwhile, PI-based regimens emerged as the more common treatment, used for $59 \%(n=421)$ of patients in the latest era.

\section{Survival and early mortality outcomes}

At data cutoff, a total of 1660 (71\%) individuals had died from any cause, including 182 (98\%), 532 (93\%), 663 (77\%), and $283(40 \%)$ individuals from eras 1 to 4 , respectively. Kaplan-Meier curves for the entire cohort are shown in Fig. 1A. Median OS increased significantly $(P<0.001)$ with a value of 4.6 years $(95 \% \mathrm{Cl}, 3.8-5.6$ years) for individuals diagnosed during the latest era, compared to 1.4 years ( $95 \% \mathrm{Cl}, 1.0-8$ years) for those diagnosed during the first era (Table 2). Survival improved most drastically between eras 1 and 2, whereas it nearly plateaued between eras 2 and 3 . The 5year OS rate increased with each era from $15 \%$ to $36 \%$ to $40 \%$ to $48 \%$, and the 10 -year OS rate from $7 \%$ to $18 \%$ to $22 \%$ (nonevaluable for era 4). The 20-year OS rate for the entire cohort was $4 \%(95 \% \mathrm{Cl}, 3-5 \%)$. In a multivariate analysis (Table 3), hazard ratios for mortality were even more drastic across eras after adjusting for baseline characteristics.

Mortality within 6 months of diagnosis decreased over time from $23 \%(95 \% \mathrm{Cl}, 18-30 \%)$ in era 1 to $13 \%(95 \% \mathrm{Cl}, 10-16 \%)$ in era 4. Individuals from the latest era who experienced early mortality (Table 4) were older in age (median, 68 years vs. 62 years) and more likely to be from an underrepresented racial/ethnic group ( $27 \%$ vs. $20 \%$ ) as compared to their surviving counterparts. They also had a higher median dFLC $(267 \mathrm{mg} / \mathrm{L})$ at baseline, predominance of cardiac involvement (92\%) and more advanced cardiac stage ( $50 \%$ with stage Illb disease).

\section{Patients aged $\geq \mathbf{7 0}$ years}

While median OS improved among patients with age at diagnosis $<70$ years from 1.5 years $(95 \% \mathrm{Cl}, 1.2-2.1$ years) to 6.6 years $(95 \%$ $\mathrm{Cl}, 5.5-7.5$ years), the improvement was marginal and statistically non-significant among patients with age $\geq 70$ years. Median OS in this older subgroup ( $N=475$, Fig. 1B) increased from 0.8 years (95\% Cl, $0.5-1.6$ years) in the first era to 2.2 years $(95 \% \mathrm{Cl}, 1.6-2.6$ years) in the last era $(P=0.101)$. Also, 6-month mortality was continually high across eras for older patients ( $23 \%$ in era 4$)$.

\section{HDM/SCT-treated patients}

Among 1581 patients with confirmed treatment, median OS was 7.6 years (95\% Cl, 6.8-8.2 years) for those who underwent $\mathrm{HDM}$ / SCT either upfront or after induction $(N=726$, Fig. 1C) and 2.9 years $(95 \% \mathrm{Cl}, 2.6-3.3$ years) for those who received only non-SCT treatments ( $N=855$, Fig. 1D). Survival improved significantly over 
Table 1. Patient characteristics and treatments by era of diagnosis.

\begin{tabular}{|c|c|c|c|c|c|c|}
\hline & $\begin{array}{l}\text { All eras } \\
(1980-2019)\end{array}$ & $\begin{array}{l}\text { Era } 1 \\
(1980-1989)\end{array}$ & $\begin{array}{l}\text { Era } 2 \\
(1990-1999)\end{array}$ & $\begin{array}{l}\text { Era } 3 \\
(2000-2009)\end{array}$ & $\begin{array}{l}\text { Era } 4 \\
(2010-2019)\end{array}$ & $P$ value \\
\hline Median age, years (IQR) & $61(53-68)$ & $59(52-66)$ & $60(52-68)$ & $60(53-68)$ & $63(56-69)$ & $<0.001$ \\
\hline Male, $n(\%)$ & $1405(60)$ & $111(60)$ & $344(60)$ & $530(61)$ & $420(59)$ & 0.830 \\
\hline Racial/ethnic minority, $n$ (\%) & $312(13)$ & $11(6)$ & $43(7)$ & $112(13)$ & $146(21)$ & $<0.001$ \\
\hline $\begin{array}{l}\text { Time to diagnosis from symptom } \\
\text { onset }(N=2095) \text {, months (IQR) }\end{array}$ & $7(2-13)$ & $10(4-17)$ & $7(3-14)$ & $7(3-13)$ & $6(1-12)$ & 0.065 \\
\hline Amyloidogenic LC, $n$ (\%) & & & & & & 0.212 \\
\hline Lambda (\%) & $1673(79)$ & $57(70)$ & $396(78)$ & $667(78)$ & $570(80)$ & - \\
\hline Kappa (\%) & $458(21)$ & $24(30)$ & $110(22)$ & $192(22)$ & $142(20)$ & - \\
\hline Median dFLC $(N=1457), \mathrm{mg} / \mathrm{L}(\mathrm{IQR})^{\mathrm{a}}$ & $90(27-252)$ & - & $136(45-285)$ & $98(30-276)$ & $76(23-219)$ & 0.229 \\
\hline \multicolumn{7}{|l|}{ Organ involvement, $n$ (\%) } \\
\hline$\geq 2$ organs $(\%)$ & $1187(53)$ & $88(62)$ & $193(37)$ & $517(60)$ & $389(55)$ & $<0.001$ \\
\hline \multicolumn{7}{|l|}{ Organ biomarkers, median (IQR) } \\
\hline $\mathrm{BNP}(N=1159), \mathrm{pg} / \mathrm{mL}$ & $202(65-574)$ & - & - & $187(57-486)$ & $216(73-630)$ & 0.038 \\
\hline Troponin-I $(N=999), \mathrm{ng} / \mathrm{mL}$ & $0.05(0.01-0.13)$ & - & - & $0.05(0.02-0.15)$ & $0.04(0.01-0.13)$ & 0.157 \\
\hline Proteinuria $(N=2089), \mathrm{g}$ per $24 \mathrm{~h}$ & $1.6(0.1-6.4)$ & $1.1(0-5.0)$ & $2.0(0.2-6.6)$ & $1.0(0.1-5.7)$ & $2.5(0.2-7.1)$ & 0.479 \\
\hline eGFR $(N=1930), \mathrm{mL} / \mathrm{min} / 1.73 \mathrm{~m}^{2}$ & $68(38-92)$ & $65(46-82)$ & $63(33-92)$ & $68(38-92)$ & $70(40-92)$ & 0.198 \\
\hline $\operatorname{ALP}(N=1914), I U / L$ & $94(71-141)$ & $84(65-142)$ & $101(78-166)$ & $95(72-142)$ & $90(69-130)$ & $<0.001$ \\
\hline \multicolumn{7}{|l|}{ BNP-based cardiac stage, $n$ (\%) } \\
\hline Stage I (\%) & $279(28)$ & - & - & $92(31)$ & $187(27)$ & 0.126 \\
\hline Stage II (\%) & $426(43)$ & - & - & $117(40)$ & $309(44)$ & 0.240 \\
\hline Melphalan-based (\%) & $570(24)$ & $57(31)$ & $243(42)$ & $241(28)$ & $29(4)$ & $<0.001$ \\
\hline IMiD-based (\%) & $362(15)$ & - & $41(7)$ & $169(20)$ & $151(21)$ & $<0.001$ \\
\hline Anti-CD38 monoclonal antibody (\%) & $92(4)$ & - & $1(<1)$ & $14(2)$ & $77(11)$ & $<0.001$ \\
\hline Other (\%) & $62(3)$ & - & $28(5)$ & $33(4)$ & $1(<1)$ & $<0.001$ \\
\hline
\end{tabular}

avalues were measured at the time of initial evaluation at the referral center and some may have instituted treatment in the community before initial evaluation. The serum free light chain assay was unavailable prior to 2003 . Testing was performed retrospectively on frozen sera of 96 patients from era 2. ${ }^{\mathrm{b}} \mathrm{BNP}$ and troponin-I were introduced in the mid-2000s.

${ }^{\mathrm{C}}$ The remaining patients did not receive therapy, or receipt of treatment could not be confirmed.

$I Q R$ interquartile range, $L C$ light chain, $d F L C$ difference between involved and uninvolved free light chains, BNP brain natriuretic peptide, eGFR estimated glomerular filtration rate by CKD-EPI equation, ALP alkaline phosphatase, $P C$ plasma cell, HDM/SCT high-dose melphalan and autologous stem cell transplantation, PI proteasome inhibitor, IMiD immunomodulatory drug.

time for both subgroups, but HDM/SCT-treated patients had particularly large gains. During eras 2-4, their 5-year OS rate improved from $54 \%$ to $63 \%$ to $76 \%$, compared to $34 \%$ to $32 \%$ to $42 \%$ for individuals treated with non-SCT therapies. Early mortality among HDM/SCT-treated patients decreased from $10 \%$ to $6 \%$ to $2 \%$, whereas for non-SCT-treated patients it decreased between eras 1 and 2 from $26 \%$ to $11 \%$, then remained fixed at $11 \%$ thereafter. Notably, 397 (55\%) patients in the HDM/SCT-treated subgroup and 197 (23\%) patients in the non-SCT subgroup received $\geq 2$ lines of treatment. Stage $\geq$ III cardiac involvement was present in $16 \%(46 / 287)$ and $35 \%(165 / 473)$ of those treated with $\mathrm{HDM} / \mathrm{SCT}$ and non-SCT therapies, respectively.

\section{Cardiac involvement}

A total of 1859 patients were evaluable for cardiac involvement based on predefined criteria; the remainder were equivocal. Among individuals with presence of cardiac involvement $(N=$ 1176, Fig. 1E), median OS improved between eras 1 and 4 from 0.9 years ( $95 \% \mathrm{Cl}, 0.6-1.3$ years) to 2.6 years $(95 \% \mathrm{Cl}, 2.4-3.5$ years). The improvement was even more drastic for patients with 
A. All patients $(\mathrm{N}=2337)$

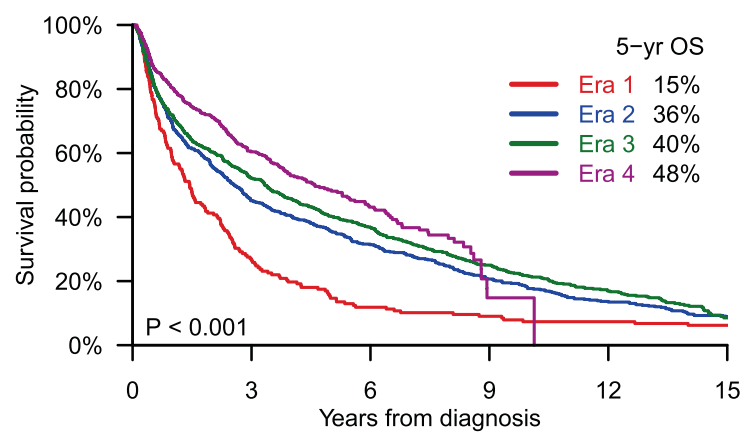

$\begin{array}{ccccccc}\text { At risk } & & & & & & \\ \text { Era 1: } & 185 & 49 & 21 & 16 & 13 & 11 \\ \text { Era 2: } & 575 & 249 & 166 & 106 & 65 & 41 \\ \text { Era 3: } & 865 & 390 & 259 & 159 & 79 & 20 \\ \text { Era 4: } & 712 & 217 & 93 & 1 & 0 & 0\end{array}$

C. HDM/SCT-treated patients $(\mathrm{N}=723)$


E. Presence of cardiac involvement $(\mathrm{N}=1176)$


B. Patients with age at diagnosis $\geq 70$ years $(N=475)$

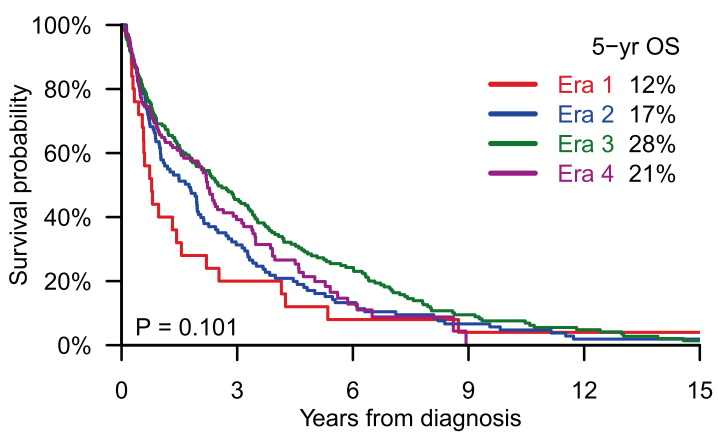

$\begin{array}{ccccccc}\text { At risk } & & & & & & \\ \text { Era 1: } & 25 & 5 & 2 & 1 & 1 & 1 \\ \text { Era 2: } & 108 & 33 & 14 & 7 & 2 & 2 \\ \text { Era 3: } & 172 & 75 & 40 & 15 & 7 & 2 \\ \text { Era 4: } & 170 & 36 & 7 & 0 & 0 & 0\end{array}$

D. Non-SCT-treated patients $(\mathrm{N}=855)$
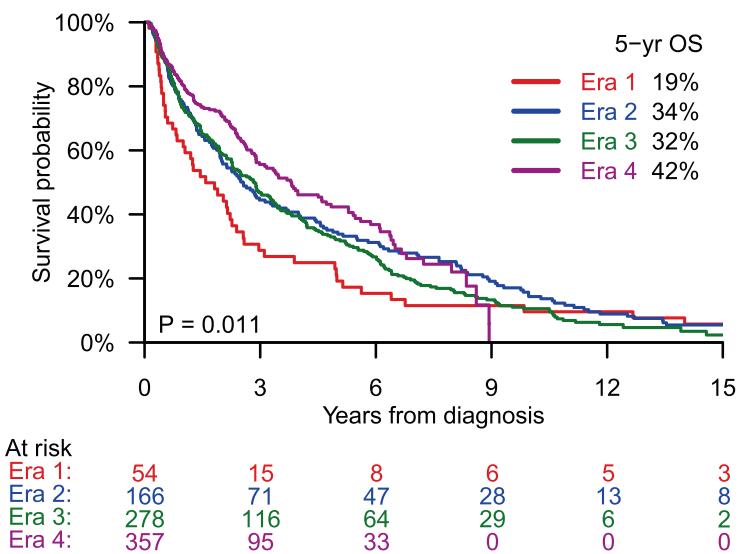

F. Absence of cardiac involvement $(\mathrm{N}=683)$

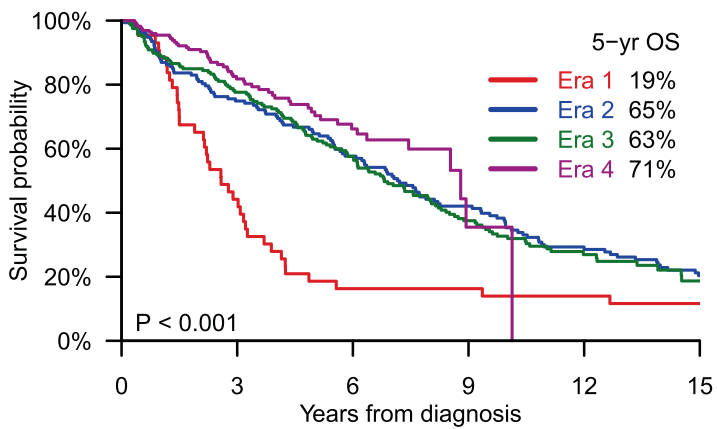

$\begin{array}{ccccccc}\text { At risk } & & & & & & \\ \text { Era 1: } & 43 & 19 & 7 & 7 & 6 & 5 \\ \text { Era 2: } & 154 & 110 & 82 & 58 & 36 & 23 \\ \text { Era 3: } & 208 & 135 & 95 & 56 & 26 & 10 \\ \text { Era 4: } & 278 & 102 & 42 & 1 & 0 & 0\end{array}$

Fig. 1 Trends in overall survival over a 40-year period among patients with AL amyloidosis. Kaplan-Meier survival curves by era of diagnosis for the entire study population (A) and patient subgroups (B-F).

absence of cardiac involvement $(N=683$, Fig. $1 \mathrm{~F})$, increasing from 2.6 years $(95 \% \mathrm{Cl}, 1.9-3.2$ years) to 8.8 years $(95 \% \mathrm{Cl}, 7.5-10.1$ years). The 5 -year OS rate for those with absence of cardiac involvement rose from $19 \%$ to $71 \%$, with the majority of this gain (46 percentage points) occurring between eras 1 and 2 . Additionally, this subgroup had a very low 6-month mortality rate of $\leq 5 \%$ across all eras. Meanwhile, early mortality was highest among patients with presence of cardiac involvement at $31 \%$
(95\% Cl, $13-42 \%)$ in era 1 , but decreased to $19 \%(95 \% \mathrm{Cl}, 15-23 \%)$ in era 4.

Among 999 patients with complete biomarker data sets, survival was analyzed according to cardiac stage (Fig. 2). There was no significant gain in survival for any BNP-based cardiac stage (I-Illb) comparing individuals diagnosed before $(N=294)$ vs. after $(N=705)$ the year 2010, when bortezomib-based regimens were introduced into practice. For patients with cardiac stage IIlb 
Table 2. Survival intervals and rates by era of diagnosis.

\begin{tabular}{|c|c|c|c|c|c|}
\hline & All eras (1980-2019) & Era 1 (1980-1989) & Era 2 (1990-1999) & Era 3 (2000-2009) & Era 4 (2010-2019) \\
\hline \multicolumn{6}{|l|}{ All patients } \\
\hline Deaths, $n(\%)$ & $1660(71)$ & $182(98)$ & $532(93)$ & $663(77)$ & $283(40)$ \\
\hline Median OS, years $(95 \% \mathrm{Cl})$ & $3.0(2.8-3.4)$ & $1.4(1.0-1.8)$ & $2.6(2.2-3.0)$ & $3.3(2.9-3.8)$ & $4.6(3.8-5.6)$ \\
\hline $\begin{array}{l}\text { 6-month mortality rate, \% } \\
(95 \% \mathrm{Cl})\end{array}$ & $16(15-18)$ & $23(18-30)$ & $17(14-21)$ & $17(14-19)$ & $13(10-16)$ \\
\hline \multicolumn{6}{|l|}{ Subgroups } \\
\hline \multicolumn{6}{|l|}{ Median OS, years $(95 \% \mathrm{Cl})$} \\
\hline Age $\geq 70$ years & $2.1(1.8-2.4)$ & $0.8(0.5-1.6)$ & $1.8(1.0-2.0)$ & $2.5(1.8-3.3)$ & $2.2(1.6-2.6)$ \\
\hline HDM/SCT-treated & $7.6(6.8-8.2)$ & - & $5.5(4.5-6.9)$ & $8.0(6.9-9.2)$ & 8.8 (8.1-NR) \\
\hline
\end{tabular}

$I Q R$ interquartile range, $O S$ overall survival, $C l$ confidence interval, NR not reached.

Table 3. Univariate and multivariate analyses of mortality risk.

\begin{tabular}{|c|c|c|c|c|}
\hline & \multicolumn{2}{|l|}{ Univariate } & \multicolumn{2}{|l|}{ Multivariate } \\
\hline & HR (95\% Cl) & $P$ value & HR (95\% Cl) & $P$ value \\
\hline Era 1 (1980-1989) & $2.06(1.70-2.49)$ & $<0.001$ & $2.70(2.04-3.57)$ & $<0.001$ \\
\hline Era 2 (1990-1999) & $1.41(1.22-1.63)$ & $<0.001$ & $1.47(1.20-1.79)$ & $<0.001$ \\
\hline Era 3 (2000-2009) & $1.29(1.12-1.48)$ & $<0.001$ & $1.29(1.10-1.52)$ & 0.002 \\
\hline Era 4 (2010-2019) & Reference & & Reference & \\
\hline Age at diagnosis & $1.02(1.02-1.03)$ & $<0.001$ & $1.03(1.03-1.04)$ & $<0.001$ \\
\hline Heart involvement & $2.27(2.00-2.57)$ & $<0.001$ & $2.33(2.03-2.69)$ & $<0.001$ \\
\hline Kidney involvement & $0.98(0.86-1.12)$ & 0.730 & $1.03(0.89-1.19)$ & 0.719 \\
\hline
\end{tabular}

$H R$ hazard ratio, $\mathrm{Cl}$ confidence interval.

disease, median OS was 0.5 years $(95 \% \mathrm{Cl}, 0.2-0.9$ years) and 1.0 years ( $95 \% \mathrm{Cl}, 0.6-1.3$ years) before vs. after 2010 , respectively; whereas 6-month mortality was $50 \%(95 \% \mathrm{Cl}, 35-68 \%)$ and $35 \%$ (95\% Cl, 27-45\%). These differences were insignificant $(P=0.756)$.

\section{Cause of death}

Primary cause of death was identified in 1160 cases (Table 5), of which 92 had confirmation by autopsy. Organ failure was the most common cause, accounting for 564 (49\%) deaths, amongst which cardiac failure predominated. Sudden unexpected death was the next most frequent cause, contributing to 266 (23\%) deaths. Cumulative incidences of the top causes of death over the course of disease are displayed in Fig. 3. Cardiac failure and sudden death decreased in proportion with longer survival from diagnosis, representing $67 \%(236 / 354)$ of deaths occurring within $\leq 6$ months; $56 \%(322 / 575)$ within $>6$ months to $\leq 5$ years; $36 \%$ (54/151) within $>5$ years to $\leq 10$ years; and $36 \%(29 / 80)$ after $>10$ years $(P<0.001)$. Compared to early-occurring deaths, those at $>5$ years after diagnosis were more frequently caused by renal failure $(18 \%)$, infections (16\%), and secondary primary malignancies (7\%). Solid tumors constituted most malignancies in this cohort: 17 of 21 cases. The remaining 4 cases were acute myeloid leukemias, thought to be therapy-related as these patients were previously treated with alkylating agents ( 2 with oral melphalan, 1 with oral melphalan followed by HDM/SCT, and 1 with cyclophosphamide).

\section{Disease-unrelated mortality}

Of 1243 deaths with known relation to disease, the majority (91\%, $n=1134$ ) were AL amyloidosis-related. The proportion of deaths not attributable to $\mathrm{AL}$ amyloidosis or its treatment increased significantly $(P<0.001)$ with each era from $3 \%(4 / 133)$ to $8 \%(36 /$ $434)$ to $8 \%(38 / 483)$ to $16 \%(31 / 193)$. AL amyloidosis-unrelated deaths also increased with longer survival from diagnosis, accounting for $2 \%(9 / 373)$ of deaths occurring within $\leq 6$ months; $8 \%(48 / 616)$ within $>6$ months to $\leq 5$ years; $16 \%(25 / 161)$ within $>5$ years to $\leq 10$ years; and $29 \%(27 / 93)$ after $>10$ years $(P<0.001)$. The most prevalent causes of AL amyloidosis-unrelated deaths were infections unrelated to treatment $(29 \%)$, major vascular events (17\%), and solid tumor malignancies (17\%).

\section{DISCUSSION}

In this longitudinal natural history study, we collected and analyzed real-world data on survival among patients with $\mathrm{AL}$ 
Table 4. Characteristics of patients from the latest era who experienced early mortality.

\begin{tabular}{|c|c|}
\hline & 2010-2019 \\
\hline$N$ & 88 \\
\hline Median age, years (IQR) & $68(59-74)$ \\
\hline Age $\geq 75$ years, $n(\%)$ & $20(23 \%)$ \\
\hline Male, $n$ (\%) & $51(58 \%)$ \\
\hline Racial/ethnic minority, $n$ (\%) & $24(27 \%)$ \\
\hline $\begin{array}{l}\text { Time to diagnosis from symptom onset, } \\
\text { months (IQR) }\end{array}$ & $8(4-16)$ \\
\hline \multicolumn{2}{|l|}{ Hematologic parameters } \\
\hline \multicolumn{2}{|l|}{ Amyloidogenic LC, $n$ (\%) } \\
\hline Lambda (\%) & $66(75)$ \\
\hline Kappa (\%) & $22(25)$ \\
\hline Median dFLC, mg/L (IQR) & $267(108-489)$ \\
\hline \multicolumn{2}{|l|}{ Organ involvement, $n(\%)$} \\
\hline Cardiac (\%) & $81(92)$ \\
\hline Renal (\%) & $58(67)$ \\
\hline Hepatic (\%) & $23(26)$ \\
\hline Nervous system (\%) & $40(46)$ \\
\hline$\geq 2$ organs $(\%)$ & $68(77)$ \\
\hline \multicolumn{2}{|l|}{ Organ biomarkers, median (IQR) } \\
\hline $\mathrm{BNP}(N=86), \mathrm{pg} / \mathrm{mL}$ & $916(393-1783)$ \\
\hline Troponin-I, ng/mL & $0.16(0.07-0.50)$ \\
\hline Proteinuria $(N=76), \mathrm{g}$ per $24 \mathrm{~h}$ & $1.3(0.3-5.6)$ \\
\hline eGFR $(N=86), \mathrm{mL} / \mathrm{min}$ per $1.73 \mathrm{~m}^{2}$ & $52(31-83)$ \\
\hline ALP, IU/L & $124(78-203)$ \\
\hline \multicolumn{2}{|l|}{ BNP-based cardiac stage $(N=86), n(\%)$} \\
\hline I (\%) & $2(2)$ \\
\hline II (\%) & $30(35)$ \\
\hline III (\%) & $11(13)$ \\
\hline IIIb (\%) & $43(50)$ \\
\hline
\end{tabular}

$I Q R$ interquartile range, $L C$ light chain, $d F L C$ difference between involved and uninvolved free light chains, BNP brain natriuretic peptide, eGFR estimated glomerular filtration rate by CKD-EPI equation, ALP alkaline phosphatase.

amyloidosis seen at a major U.S. referral center. Median OS improved from 1.4 years in the 1980s to 4.6 years in the 2010 s. This finding is in line with a study of patients with $\mathrm{AL}$ amyloidosis from the U.K., which reported an increase in survival from 17 months (1.4 years) in 1987-2005 to 51 months (4.25 years) in 2011-2015 [24]. The observed 5-year OS rate of $48 \%(95 \% \mathrm{Cl}$, $43-53 \%)$ in the latest era of our study, however, falls short of the relative 5 -year OS rate of $55.6 \%(95 \% \mathrm{Cl}, 54.9-56.3 \%)$ that was estimated for multiple myeloma in 2011-2017 [37], supporting the contention that these two diseases- although related-have divergent natural histories.

Additionally, we found that 6-month mortality decreased over our study period from $23 \%$ to $13 \%$. This outcome contrasts earlier observations from both the Mayo Clinic and U.K. showing unchanging rates of early mortality. From 1977 to 2006, 43-46\% of patients in the Mayo Clinic cohort were dying within one year of diagnosis [22]. In an update from the same center, 6-month mortality had abated for the first time after 2005, decreasing from a rate of $37 \%$ to $25 \%$ [23]. The lower early mortality rates observed in our study compared to other centers may be attributed to our institution being a major transplantation referral site, drawing younger and fitter patients with earlier-stage disease. One epidemiologic study suggested that the median age of patients with $\mathrm{AL}$ amyloidosis in the general population may, in fact, be over a decade older (i.e., 76 years) than that observed in our referred cohort [21]. Median age at diagnosis in our population was 61 years, whereas in the Mayo Clinic and U.K. cohorts was 63 and 66 years, respectively $[22,23]$. Moreover, the distribution of cardiac stages I-III was $28 \%, 43 \%$ and $29 \%$ (BNP-based staging system) in our cohort, compared to $21 \%, 28 \%$ and $41 \%$ (Mayo 2004 staging system) in the Mayo Clinic cohort [23]. The survival trends portrayed in this study reflect the effects of institutional and community factors, in addition to global developments in communication, technology and medicine. Key predictors of survival in $\mathrm{AL}$ amyloidosis are the severity of cardiac involvement and the effectiveness of treatments to attain deep and durable hematologic responses [18]. We observed increasing receipt of $\geq 2$ lines of therapy over time, owing to more available options for relapsed/refractory AL amyloidosis [38], which are adopted from the therapeutic landscape for multiple myeloma. Due to the pathological nature of AL amyloidosis, disease awareness and timely detection at the community level are also critical for survival outcomes. The pathway to diagnosis can be long and complicated. In an advocacy group-led questionnaire study, over one-third of patients with $\mathrm{AL}$ amyloidosis reported that their symptoms preceded diagnosis by more than one year [39]. Longer diagnostic interval was independently associated with higher risk of death in a recent report from our center [40]. However, findings from the current study provide grounds for optimism. The median time to diagnosis from symptom onset was shortened across the eras by 4 months. Earlier disease recognition in the community may explain the declining early mortality rate found in our study.

Understanding the differing evolution of survival amid patient subgroups can identify those with higher disease burden and guide future research efforts towards areas of greatest value. An analysis of the distribution of survival gains in the $A L$ amyloidosis population is needed. In this study, we detected significant improvements in survival over time for subgroups based on cardiac involvement and receipt of HDM/SCT, but not for patients with age at diagnosis $\geq 70$ years. Older individuals with $A L$ amyloidosis face distinct clinical challenges [41, 42]. Adverse effects from multiorgan dysfunction in the presence of comorbidities, coupled with poor tolerance of therapies, are magnified in this subgroup. In the latest era of our study, older patients had the highest rate of early mortality. Future efforts for earlier disease recognition are needed for this subgroup. Overcoming these challenges is increasingly important as the median age at diagnosis of $\mathrm{AL}$ amyloidosis rises and as more patients survive into older age.

Amongst subgroups based on cardiac involvement and HDM/ SCT receipt, survival gains were unevenly distributed. Individuals with absence of cardiac involvement had the greatest improvement with median OS increasing $>6$ years over the study period. The steepest increase occurred between eras 1 and 2, likely due to the introduction of $\mathrm{HDM} / \mathrm{SCT}$. Comparatively, patients with presence of cardiac involvement attained smaller gains at $<2$ years in total. For those with cardiac stage I/II disease, there was an apparent but non-significantly higher early mortality rate in the modern era (post-2010 vs. pre-2010), thought to be due to statistical probability and bias from censorship of patients lost to follow-up. Meanwhile, for those with cardiac stage III/IIIb disease who are generally ineligible for aggressive treatment with HDM/ SCT, survival was found not to have improved with the arrival of bortezomib-based regimens in 2010. Thus, more effective management strategies for patients with advanced amyloid cardiomyopathy are still needed.

HDM/SCT-treated individuals had the highest 5-year OS rate in the latest era, reflecting the potential long-term benefits of this treatment in $\mathrm{AL}$ amyloidosis with respect to durable hematologic and organ responses $[6,26,27,43]$. The $>3$ year improvement in 


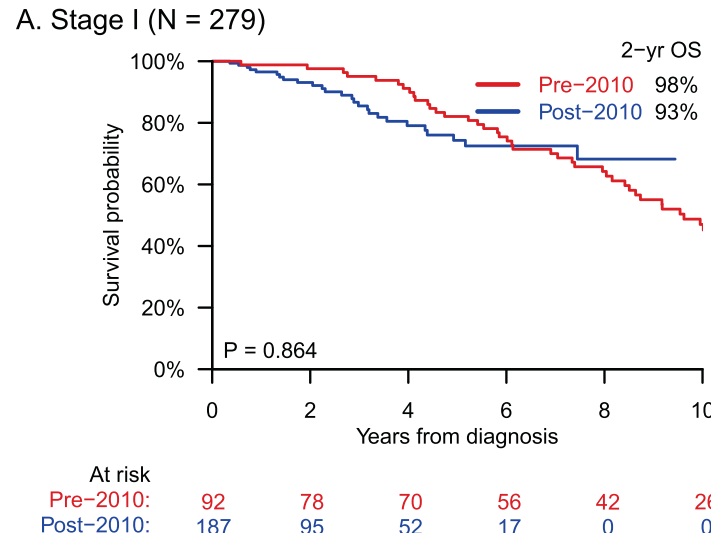

C. Stage III ( $\mathrm{N}=139)$

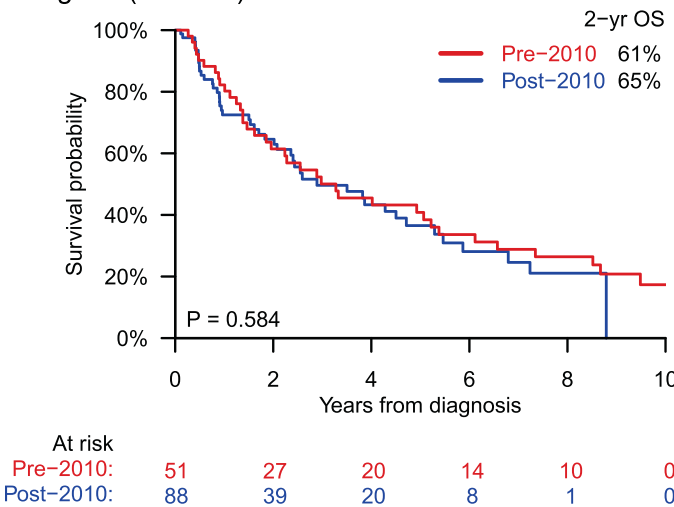

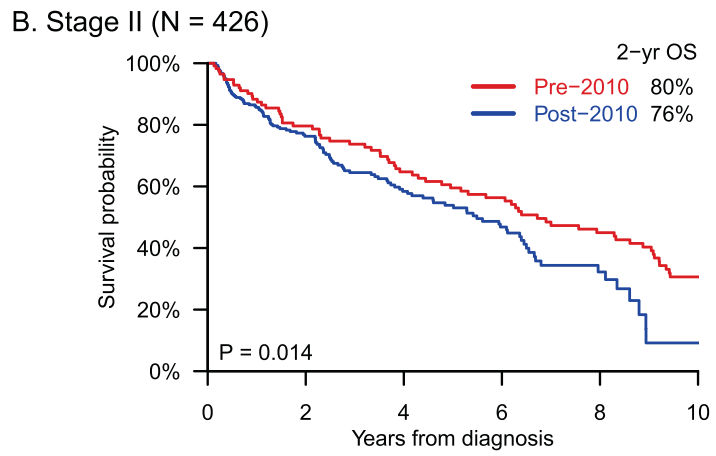

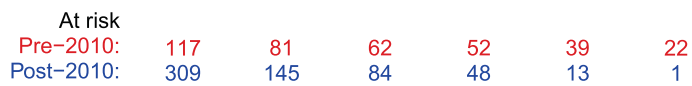

D. Stage IIIb $(\mathrm{N}=155)$

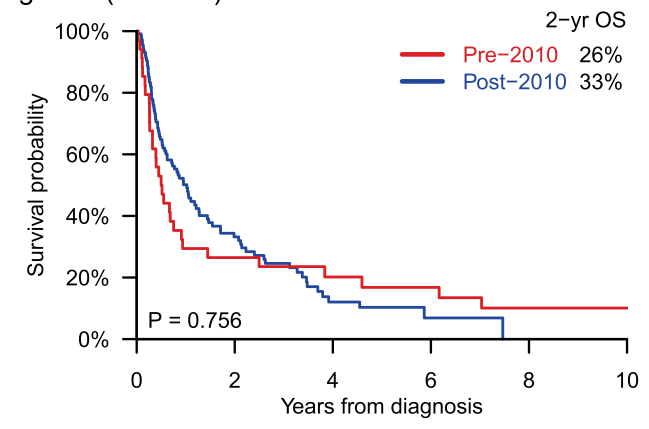

At risk

Pre-2010:

Post-2010:

Fig. 2 Survival according to BNP-based cardiac stage before and after 2010. Despite the introduction of bortezomib-based regimens in 2010, survival did not improve significantly for any cardiac stage I-IIlb, as shown in panels (A-D), respectively. Complete biomarker data sets (BNP and troponin-I) were not available until 2007. Accordingly, pre-2010 and post-2010 consisted of patients diagnosed in 2007-2009 and 2010-2019, respectively. The apparent decline in survival for cardiac stage II disease (B) may be the result of censorship bias due to shorter follow-up for the post-2010 group.

median OS over time observed in this subgroup may be explained by several factors: (1) improved experience with HDM/SCT in AL amyloidosis, (2) more stringent selection of favorable-risk patients as alternative therapies became available [44], and (3) the ability of $\mathrm{HDM} / \mathrm{SCT}$-eligible patients to tolerate sequential treatments as over one-half received $\geq 2$ lines of therapy.

Few studies to date have focused on primary causes of death in $\mathrm{AL}$ amyloidosis and how these may change over the course of disease. Available knowledge relies primarily on autopsy studies from the 1980 s, in which about $40 \%$ of deaths were attributed to progression of cardiac dysfunction or arrhythmias [1, 28]. Autopsy data may not accurately reflect the broader population as cases with more apparent causes of death are less likely to undergo postmortem examination. Our study provides a contemporary report of primary causes of death in a large patient cohort. The most frequent causes were cardiac failure and sudden unexpected death, which together comprised $55 \%$ of deaths. Nearly 1 in 3 deaths occurring within 6 months of diagnosis were due to sudden deaths, of which the underlying mechanisms in $A L$ amyloidosis are believed to be electromechanical dissociation (i.e., pulseless electrical activity), unrecognized conduction system disease, thromboembolic events, or abrupt dysautonomia $[3,29,45-49]$.

We noted shifts in primary causes of death across disease course. Cardiac failure and sudden death together accounted for $36 \%$ of late-occurring deaths, compared to $67 \%$ of early-occurring deaths. Meanwhile, renal failure emerged as an important cause of late-occurring deaths. Among long-term survivors, more deaths were also associated with environmental and patient risk factors, such as infections and solid tumor malignancies, indicating potential lasting effects of this disease and its therapies on the host. With longer prospective analysis, these non-cardiac causes of death may be found to be even more prominent.

The majority of deaths captured in our study were directly related to $\mathrm{AL}$ amyloidosis. Even among long-term survivors, progression of amyloid organ dysfunction was the top cause. Novel therapies targeting amyloid deposits in tissues, rather than the production of precursor light chains by clonal plasma cells, may enhance organ recovery for these patients. Several antiamyloid monoclonal antibodies are presently under investigation (e.g., NEOD001 and CAEL-101) [50, 51]. Moreover, advanced tools for disease surveillance, such as minimal residual disease (MRD) assessment, may better prognosticate the risk of late-occurring disease-related events among long-term survivors. One study found that nearly $40 \%$ of patients with a durable hematologic complete response over 5 years from last treatment still harbored a detectable clonal plasma cell population by MRD testing [52]. Despite the high proportion of AL amyloidosis-related deaths in our study, there was a significant decline over time. In the latest era, $16 \%$ of deaths were from disease-unrelated causes, compared to $3 \%$ in the first era. More disease-unrelated deaths are likely to be captured with longer prospective observation. This has the potential to create competing risks in conventional survival analysis, leading to an overestimation of disease risk. Adopting cause-specific frameworks for survival assessment of AL amyloidosis may be beneficial in the future. 
Table 5. Primary causes of death in the AL amyloidosis cohort.

\begin{tabular}{|c|c|c|c|c|c|}
\hline & All deaths & $\begin{array}{l}\text { Early deaths } \\
\text { ( } \leq 6 \text { months) }\end{array}$ & $\begin{array}{l}\text { Late deaths } \\
\text { ( }>5 \text { years) }\end{array}$ & $\begin{array}{l}\text { Disease- } \\
\text { related deaths }\end{array}$ & $\begin{array}{l}\text { Disease-unrelated } \\
\text { deaths }^{\mathrm{a}}\end{array}$ \\
\hline Organ failure (\%) & $564(49)$ & $169(48)$ & $94(41)$ & $558(54)$ & $6(6)$ \\
\hline Renal (\%) & $124(11)$ & $13(4)$ & $41(18)$ & $121(12)$ & $3(3)$ \\
\hline Hepatic (\%) & $37(3)$ & $22(6)$ & $2(1)$ & $37(4)$ & $0(0)$ \\
\hline Infection and/or sepsis (\%) & $125(11)$ & $25(7)$ & $36(16)$ & $95(9)$ & $30(29)$ \\
\hline Treatment-related event (\%) & $49(4)$ & $16(5)$ & $9(4)$ & $39(4)$ & $10(10)$ \\
\hline $\begin{array}{l}\text { Major vascular event (stroke, MI, } \\
\text { VTE) (\%) }\end{array}$ & $48(4)$ & $19(5)$ & $8(3)$ & $31(3)$ & $17(17)$ \\
\hline Hemorrhage (\%) & $33(3)$ & $12(3)$ & $10(4)$ & $29(3)$ & $4(4)$ \\
\hline
\end{tabular}

${ }^{a}$ Deaths occurring while in remission and off plasma cell-directed treatment, or with clear relation to a co-morbid condition. Relation to AL amyloidosis was evaluable for 98 cases despite an unidentified primary cause of death.

${ }^{\mathrm{b}}$ Cardiac failure includes $36(10 \%)$ cardiac arrhythmia events.

'There were 15 patients with sudden death for whom relation to AL amyloidosis was uncertain.

MI myocardial infarction, VTE venous thromboembolism.

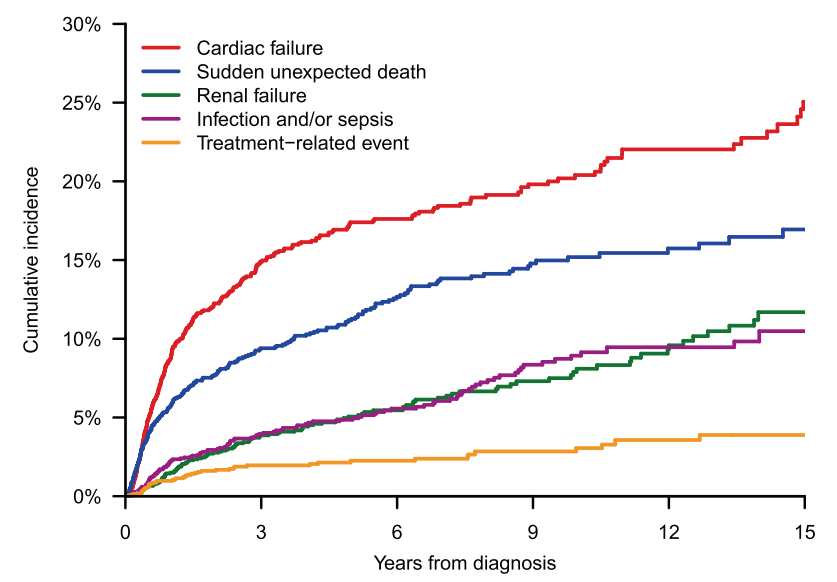

Fig. 3 Cumulative incidences of the top causes of death across disease course. The rate of cardiac failure and sudden unexpected deaths decreased with longer survival time from diagnosis.

Limitations of our study include its single-center, nonprospective design and lack of complete data for all patients. Long-term survival was underrepresented in the later eras due to shorter duration of follow-up. Similarly, this study did not collect robust data on causes of death among long-term survivors, a group that is at greater risk for AL amyloidosis-unrelated causes, because many were alive at data cutoff. Cases with unidentified primary cause of death were also more likely to occur later in disease course and be deemed AL amyloidosis-unrelated. Thus, disease-unrelated mortality is believed to be underestimated in our analysis. Referral center bias may account for higher utilization of HDM/SCT in our study compared to other reports, particularly during era 2 when there was a lack of alternative non-SCT therapies. Median OS may be overestimated and early mortality underestimated as referral bias may enrich our cohort for healthier individuals who have superior survival. We were unable to control for changing referral patterns over time, particularly with regard to cardiac stage as biomarkers were unavailable before 2007. Despite these limitations, this study was strengthened by its large cohort and portrayal of a real-world perspective on survival in $A L$ amyloidosis.

\section{CONCLUSIONS}

In order to support future drug development in rare diseases like AL amyloidosis, the U.S. Food and Drug Administration issued a framework in March 2019 for the conduct of natural history studies [53]. By providing insights into disease outcomes in realworld practice, these studies help to define appropriate endpoints and observation periods in clinical trials, and can serve as external comparator arms. The present study provides natural history information on survival and mortality in a large cohort of patients with $\mathrm{AL}$ amyloidosis, redefining median OS in the modern era to be 4.6 years. To sustain this progress, ongoing strategies for early disease detection, collaborative clinical trials, along with equitable delivery of care are essential.

\section{REFERENCES}

1. Kyle RA, Greipp PR. Amyloidosis (AL): clinical and laboratory features in 229 cases. Mayo Clin Proc 1983;58:665-83.

2. Skinner M, Anderson J, Simms R, Falk R, Wang M, Libbey C. et al. Treatment of 100 patients with primary amyloidosis: a randomized trial of melphalan, prednisone, and colchicine versus colchicine only. Am J Med. 1996;100:290-8.

3. Dubrey SW, Cha K, Anderson J, Chamarthi B, Reisinger J, Skinner M, et al. The clinical features of immunoglobulin light-chain (AL) amyloidosis with heart involvement. QJM 1998;91:141-57.

4. Majolino I, Marcenò R, Pecoraro G, Scimé R, Vasta S, Liberti G, et al. High dose therapy and autologous transplantation in amyloidosis-AL. Haematologica 1993;78:68-71.

5. Comenzo RL, Vosburgh E, Simms RW, Bergethon P, Sarnacki D, Finn K, et al. Doseintensive melphalan with blood stem cell support for the treatment of $A L$ amyloidosis: one-year follow-up in five patients. Blood1996;88:2801-6.

6. Sanchorawala V, Sun F, Quillen K, Sloan JM, Berk JL, Seldin DC. Long-term outcome of patients with $\mathrm{AL}$ amyloidosis treated with high-dose melphalan and stem cell transplantation: 20-year experience. Blood.2015;126:2345-7. 
7. Mikhael JR, Schuster SR, Jimenez-Zepeda VH, Bello N, Spong J, Reeder CB, et al. Cyclophosphamide-bortezomib-dexamethasone (CyBorD) produces rapid and complete hematologic response in patients with AL amyloidosis. Blood 2012;119:4391-4.

8. Palladini G, Sachchithanantham S, Milani P, Gillmore J, Foli A, Lachmann H, et al. A European collaborative study of cyclophosphamide, bortezomib, and dexamethasone in upfront treatment of systemic AL amyloidosis. Blood 2015;126:612-5.

9. Sanchorawala V, Palladini G, Kukreti V, Zonder JA, Cohen AD, Seldin DC, et al. A phase $1 / 2$ study of the oral proteasome inhibitor ixazomib in relapsed or refractory AL amyloidosis. Blood 2017;130:597-605.

10. Dispenzieri A, Buadi F, Laumann K, LaPlant B, Hayman SR, Kumar SK, et al. Activity of pomalidomide in patients with immunoglobulin light-chain amyloidosis. Blood 2012;119:5397-404.

11. Sanchorawala V, Shelton AC, Lo S, Varga C, Sloan JM, Seldin DC. Pomalidomide and dexamethasone in the treatment of $A L$ amyloidosis: results of a phase 1 and 2 trial. Blood 2016;128:1059-62.

12. Kaufman GP, Schrier SL, Lafayette RA, Arai S, Witteles RM, Liedtke M. Daratumumab yields rapid and deep hematologic responses in patients with heavily pretreated AL amyloidosis. Blood 2017;130:900-2.

13. Sanchorawala $V$, Sarosiek $S$, Schulman $A$, Mistark $M$, Migre $M E$, Cruz $R$, et al Safety, tolerability, and response rates of daratumumab in relapsed $A L$ amyloidosis: results of a phase II study. Blood 2020;135:1541-7.

14. Dispenzieri A, Gertz MA, Kyle RA, Lacy MQ, Burritt MF, Therneau TM, et al. Serum cardiac troponins and $\mathrm{N}$-terminal pro-brain natriuretic peptide: a staging system for primary systemic amyloidosis. J Clin Oncol.2004;22:3751-7.

15. Kumar S, Dispenzieri A, Lacy MQ, Hayman SR, Buadi FK, Colby C, et al. Revised prognostic staging system for light chain amyloidosis incorporating cardiac biomarkers and serum free light chain measurements. J Clin Oncol. 2012;30:989-95.

16. Lilleness B, Ruberg FL, Mussinelli R, Doros G, Sanchorawala V. Development and validation of a survival staging system incorporating BNP in patients with light chain amyloidosis. Blood 2019;133:215-23.

17. Gertz MA, Lacy MQ, Dispenzieri A, Hayman SR. Amyloidosis: diagnosis and management. Clin Lymphoma Myeloma 2005;6:208-19.

18. Palladini G, Dispenzieri A, Gertz MA, Kumar S, Wechalekar A, Hawkins PN, et al. New criteria for response to treatment in immunoglobulin light chain amyloidosis based on free light chain measurement and cardiac biomarkers: impact on survival outcomes. J Clin Oncol 2012;30:4541-9.

19. Palladini G, Hegenbart U, Milani $P$, Kimmich $C$, Foli $A$, Ho AD, et al. A staging system for renal outcome and early markers of renal response to chemotherapy in AL amyloidosis. Blood 2014;124:2325-32.

20. Quock TP, Yan T, Chang E, Guthrie S, Broder MS. Epidemiology of AL amyloidosis: a real-world study using US claims data. Blood Adv. 2018;2:1046-53.

21. Kyle RA, Larson DR, Kurtin PJ, Kumar S, Cerhan JR, Therneau TM, et al. Incidence of AL amyloidosis in olmsted county, Minnesota, 1990 through 2015. Mayo Clin Proc 2019;94:465-71.

22. Kumar SK, Gertz MA, Lacy MQ, Dingli D, Hayman SR, Buadi FK, et al. Recent improvements in survival in primary systemic amyloidosis and the importance of an early mortality risk score. Mayo Clin Proc 2011;86:12-18.

23. Muchtar E, Gertz MA, Kumar SK, Lacy MQ, Dingli D, Buadi FK, et al. Improved outcomes for newly diagnosed AL amyloidosis between 2000 and 2014: cracking the glass ceiling of early death. Blood 2017;129:2111-9.

24. Ravichandran S, Lachmann HJ, Wechalekar AD. Epidemiologic and survival trends in amyloidosis, 1987-2019. N Engl J Med. 2020;382:1567-8.

25. Muchtar E, Gertz MA, Lacy MQ, Go RS, Buadi FK, Dingli D, et al. Ten-year survivors in $\mathrm{AL}$ amyloidosis: characteristics and treatment pattern. $\mathrm{Br} J$ Haematol 2019;187:588-94.

26. Sidana S, Sidiqi MH, Dispenzieri A, Buadi FK, Lacy MQ, Muchtar E, et al. Fifteen year overall survival rates after autologous stem cell transplantation for $A L$ amyloidosis. Am J Hematol 2019;94:1020-6.

27. Sharpley FA, Petrie A, Mahmood S, Sachchithanantham S, Lachmann HJ, Gillmore JD, et al. A 24-year experience of autologous stem cell transplantation for light chain amyloidosis patients in the United Kingdom. Br J Haematol 2019;187:642-52.

28. Roberts WC, Waller BF. Cardiac amyloidosis causing cardiac dysfunction: analysis of 54 necropsy patients. Am J Cardiol 1983;52:137-46.

29. Grogan M, Dispenzieri A. Natural history and therapy of AL cardiac amyloidosis. Heart Fail Rev 2015;20:155-62.

30. Bahlis NJ, Lazarus HM. Multiple myeloma-associated AL amyloidosis: is a distinctive therapeutic approach warranted? Bone Marrow Transplant 2006;38:7-15.

31. Mendelson L, Shelton A, Brauneis D, Sanchorawala V. AL amyloidosis in myeloma: red flag symptoms. Clin Lymphoma Myeloma Leuk 2020;20:777-8.

32. Sanchorawala V, Blanchard E, Seldin DC, O'Hara C, Skinner M, Wright DG. AL amyloidosis associated with B-cell lymphoproliferative disorders: frequency and treatment outcomes. Am J Hematol 2006;81:692-5.

33. Sidana S, Larson DP, Greipp PT, He R, McPhail ED, Dispenzieri A. et al. IgM AL amyloidosis: delineating disease biology and outcomes with clinical, genomic and bone marrow morphological features. Leukemia. 2020;34:1373-82.
34. Basset M, Defrancesco I, Milani P, Nuvolone M, Rattotti S, Foli A, et al. Nonlymphoplasmacytic lymphomas associated with light-chain amyloidosis. Blood 2020;135:293-6.

35. Wechalekar AD, Chakraborty R, Lentzsch S. Systemic amyloidosis due to lowgrade lymphoma. Hematol Oncol Clin North Am 2020;34:1027-39.

36. Gertz MA, Comenzo R, Falk RH, Fermand JP, Hazenberg BP, Hawkins PN, et al. Definition of organ involvement and treatment response in immunoglobulin light chain amyloidosis ( $\mathrm{AL}$ ): a consensus opinion from the 10th International Symposium on Amyloid and Amyloidosis, Tours, France, 18-22 April 2004. Am J Hematol 2005;79:319-28.

37. Howlader, N SEER Cancer Statistics Review, 1975-2018 (National Cancer Institute, Bethesda, 2021).

38. Sarosiek S, Sanchorawala V. Treatment options for relapsed/refractory systemic light-chain (AL) amyloidosis: current perspectives. J Blood Med 2019;10:373-80.

39. Lousada I, Comenzo RL, Landau H, Guthrie S, Merlini G. Light chain amyloidosis: patient experience survey from the amyloidosis research consortium. Adv Ther 2015;32:920-8.

40. Schulman A, Connors LH, Weinberg J, Mendelson LM, Joshi T, Shelton AC. et al Patient outcomes in light chain (AL) amyloidosis: The clock is ticking from symptoms to diagnosis. Eur J Haematol. 2020;105:495-501.

41. Sachchithanantham S, Offer M, Venner C, Mahmood SA, Foard D, Rannigan L. et al. Clinical profile and treatment outcome of older ( $>75$ years) patients with systemic AL amyloidosis. Haematologica. 2015;100:1469-76.

42. Acevedo J, Doros G, Szalat R, Sanchorawala V. Clinical characteristics, treatment regimens, and survival in elderly patients with $\mathrm{AL}$ amyloidosis. Clin Lymphoma Myeloma Leuk 2021;21:425-6.

43. Browning S, Quillen K, Sloan JM, Doros G, Sarosiek S, Sanchorawala V. Hematologic relapse in $\mathrm{AL}$ amyloidosis after high-dose melphalan and stem cell transplantation. Blood 2017;130:1383-6.

44. Dispenzieri A, Lacy MQ, Kyle RA, Therneau TM, Larson DR, Rajkumar SV, et al. Eligibility for hematopoietic stem-cell transplantation for primary systemic amyloidosis is a favorable prognostic factor for survival. J Clin Oncol 2001;19:3350-6.

45. Falk RH, Rubinow A, Cohen AS. Cardiac arrhythmias in systemic amyloidosis: correlation with echocardiographic abnormalities. J Am Coll Cardiol. 1984;3:107-13.

46. Chamarthi B, Dubrey SW, Cha K, Skinner M, Falk RH. Features and prognosis of exertional syncope in light-chain associated AL cardiac amyloidosis. Am J Cardiol 1997:80:1242-5

47. Sidana S, Tandon N, Brady PA, Grogan M, Gertz MA, Dispenzieri A, et al. Prog nostic significance of holter monitor findings in patients with light chain amyloidosis. Mayo Clin Proc. 2019;94:455-64.

48. Feng D, Edwards WD, Oh JK, Chandrasekaran K, Grogan M, Martinez MW, et al. Intracardiac thrombosis and embolism in patients with cardiac amyloidosis. Circulation 2007;116:2420-6.

49. Bever KM, Masha LI, Sun F, Stern L, Havasi A, Berk JL, et al. Risk factors for venous thromboembolism in immunoglobulin light chain amyloidosis. Haematologica 2016;101:86-90.

50. Gertz MA, Landau H, Comenzo RL, Seldin D, Weiss B, Zonder J, et al. First-inhuman phase I/II study of NEOD001 in patients with light chain amyloidosis and persistent organ dysfunction. J Clin Oncol 2016;34:1097-103.

51. Edwards CV, Bhutani D, Mapara M, Radhakrishnan J, Shames S, Maurer MS, et al. One year follow up analysis of the phase $1 \mathrm{a} / \mathrm{b}$ study of chimeric fibril-reactive monoclonal antibody 11-1F4 in patients with AL amyloidosis. Amyloid 2019;26:115-6.

52. Staron A, Burks EJ, Lee JC, Sarosiek S, Sloan JM, Sanchorawala V. Assessment of minimal residual disease using multiparametric flow cytometry in patients with AL amyloidosis. Blood Adv 2020;4:80-884.

53. Rare Diseases: Natural History Studies for Drug Development; Guidance for Industry; Draft Guidance. Report No.: FDA-2019-D-0481-0002 (U.S. Food and Drug Administration, Silver Spring, 2019).

\section{ACKNOWLEDGEMENTS}

The Amyloidosis Center database and repository are supported by the Amyloid Research Fund of Boston University School of Medicine. The authors acknowledge the founding director, Dr. Martha Skinner, for her vision in launching and maintaining the database. The authors also thank their colleagues from the multidisciplinary team for the care of patients in this study.

\section{AUTHOR CONTRIBUTIONS}

AS: conceptualization and design, collection and assembly of data, data analysis and interpretation, and writing of manuscript. LZ and GD: statistical analysis and interpretation. LHC: curation of data from database. LMM and TJ: maintenance of the database. VS: conceptualization, supervision, and approval of final draft. All authors provided critical revisions to the manuscript. 
10

\section{CONFLICT OF INTEREST}

The authors declare no competing interests.

\section{ADDITIONAL INFORMATION}

Correspondence and requests for materials should be addressed to V.S.

Reprints and permission information is available at http://www.nature.com/ reprints

Publisher's note Springer Nature remains neutral with regard to jurisdictional claims in published maps and institutional affiliations.
Open Access This article is licensed under a Creative Commons Attribution 4.0 International License, which permits use, sharing, adaptation, distribution and reproduction in any medium or format, as long as you give appropriate credit to the original author(s) and the source, provide a link to the Creative Commons license, and indicate if changes were made. The images or other third party material in this article are included in the article's Creative Commons license, unless indicated otherwise in a credit line to the material. If material is not included in the article's Creative Commons license and your intended use is not permitted by statutory regulation or exceeds the permitted use, you will need to obtain permission directly from the copyright holder. To view a copy of this license, visit http://creativecommons. org/licenses/by/4.0/.

(c) The Author(s) 2021 